\title{
Organisational Compassion and Employee Engagement in Virtual Work Environments during Covid-19 Lockdown in Uganda and Rwanda
}

\author{
Hannah Muzee \\ Stellenbosch University, South Africa \\ muzhann2002@gmail.com
}

James Kizza

University of Kisubi, Uganda

George Mulingi Mugabe

Kepler, Rwanda

Purpose: This study attempted to study the dynamics between organisational compassion and employee engagement during the COVID-19 lockdowns in Uganda and Rwanda when workers were required to work from home and in Virtual work environments.

Methodology/approach: The study adopted a quantitative research design. Data was collected from a sample of staff in selected institutions of higher learning in Uganda and Rwanda using an online questionnaire distributed both through social media and email correspondence.

Findings: The findings indicated that organisational compassion was a significant predictor of the vigour component of employee engagement compared to dedication and absorption while working virtually. Moreover, for selected organisational compassion dimensions of mindfulness and kindness, the supervisor's kindness towards employees and employees' mindfulness of self to others were strong predictors of work engagement while working remotely.

Originality/value: While organisational compassion and employee engagement have been studied in in-person settings, this paper attempted to explore these concepts in virtual and remote workspaces with unique complexities.

Keywords: Employee Engagement; Organizational Compassion; Virtual work; Work remotely; Well-being

\section{Introduction}

It is no doubt that virtual work environments have always been an alternative, especially in the $21^{\text {st }}$ century and a fast-growing trend. However, their possibility was never considered mainstream given the different intricacies that pertained to their management, such as supervisory mechanisms. In a world where it is generally believed that physical presence is synonymous with work productivity, the complexities of measuring work productivity, let alone keeping employees engaged while working virtually, are now imminent. Even though global financial pressures had pushed some organisations to consider virtual workspaces, it wasn't a reality that many saw coming to their doorsteps. The COVID-19 pandemic brought the future of work right into the present, almost threatening to make it mainstream.

Apart from changing the way of life for people worldwide, it brought many economies and companies to the brink of collapse. With social and work patterns disputed, companies and organisations had to adjust their modus operandi quickly. Moreover, given the high risk of infections and raising numbers of fatalities, isolation was paramount. Hence, many employers were encouraged to prioritise the health and protection of their workers and families by considering virtual work arrangements (International Labour Organisation [ILO], 2020). 
Virtual work arrangements became feasible with advancements in technology like the rise in internet use (Chen, 2012; Powell et al., 2004). The internet and computer-driven technologies enabled work management across time and space boundaries (Peters \& Manz, 2007). These telecommuting technologies have helped companies and organisations cut down on overhead costs and improved employee productivity. A study by Okechukwu et al. (2017) on virtual management and employee performance in selected e-businesses in Lagos State, Nigeria, found that virtual communication and collaboration significantly affected employee effectiveness and productivity, respectively. The increase in productivity and effectiveness was attributed to increased self-esteem that arose out of increased trust felt by the employees from their supervisors.

Despite the apparent advantage of virtual work arrangements, especially with the advent of COVID-19, there are several challenges that workers/employees have to grapple with. First, opponents of virtual work environments fault them for limited social interactions and knowledge sharing, usually possible in close physical contact at a workplace. Besides, when workers are isolated, the likelihood of stress is apparent, which may cause their productivity to be deep (Schepp \& Schepp, 1995).

The success of virtual workspaces is dependent on several factors, such as virtual collaboration. Virtual collaboration demonstrated by a member of a virtual team ensures productive work and drives engagement. The success of virtual teams is thus facilitated by good communication skills, high emotional intelligence, ability to work independently and manage stressful situations (Davies et al., 2011). Managing stressful situations requires more than empathy but also understanding to win employee trust and enhance work engagement. While work engagement has been explored in, in-person work setting, this study attempted to investigate employee engagement in the virtual work setting and its interplay with organisational compassion. The remainder of the paper is organised as follows: Section 2 describes the conceptual and theoretical literature, Section 3 describes the research design, data collection and data analysis methods applied, Section 4 presents the study findings, while Section 5 the discussion and conclusion.

\section{Conceptual and theoretical literature}

Compassion is the willingness and desire to express kindness to others or being thoughtful and aware of another's experiences. While compassion is related and rooted in empathy, it requires a more profound sense of understanding that involves seeing others as part of self and relating to what they are experiencing at a much deeper level. Compassion could also be an interpersonal process that involves noticing, feeling, sense-making, and acting in ways that alleviate the suffering of another (Dutton et al., 2014); thus expressed in feelings of affection, care, and tenderness towards subordinates or colleagues without the expectation for specific organisational benefit (Eldor, 2018). Consequently, in an organisation with the compassion, employees perceive themselves as being favourably treated by others' will to help them out of or in a challenging work environment. Thus, expression of compassion is evident in one being open and moved by the suffering of others that one desires to ease their suffering. It is manifested in kindness, mindfulness, and common humanity to others plight (Neff, 2003).

Mindfulness is believed to have roots in Buddhism and is defined as "a state of consciousness in which attention is focused on a present phenomenon occurring both externally and internally" (Dane, 2011:1000). Mindfulness involves being consciously present in one's mind, body, and surroundings (Andersson \& Engervall, 2017). Concerning suffering, it facilitates the awareness manifested in the emotional balance between self and others (Pommier, 2010). It also requires an appreciation of the present moment's awareness with an observable and non-judgmental stance (Wiroko \& Evanytha, 2019). When employees are trained in mindfulness, it improves 
their well-being and makes them more relaxed, focused, and able to manage stressful situations (Andersson \& Engervall, 2017; Carmody \& Baer, 2008; Ume \& Javed, 2019; Weinstein et al., 2009). Because employees can notice suffering in work contexts, expression of mindfulness means that they accept the situation for what it is and find creative and innovative ways of addressing their suffering while engaging in work. Therefore, employees with a mindful attribute have a high likelihood of satisfaction with their work, thus remain engaged on the job and absorbed (Atkins \& Parker, 2012; Datu \& Park, 2019; Rich et al., 2010). Therefore, an attitude of mindfulness is crucial among employees, and it is also paramount that organisational leaders signal the importance of mindfulness to employees (Vogus \& Sutcliffe, 2012).

In consort with mindfulness is kindness which means extending kindness and understanding to oneself and others. In situations of failure or suffering, compassion offers kindness to oneself and others without being critical or indifferent (Pommier, 2010). At the same time, kindness is associated with outcomes of happiness, optimism, and life satisfaction. It increases the recipient and the giver's well-being and an individual's tendency to perform favours and good actions to the benefit of others (Cotney \& Banerjee, 2019; Park \& Peterson, 2006). These compassion elements (mindfulness and kindness) are embedded in the personal, relational, and organisational contexts. Compassion is one of the suggested tools to manage suffering and employees' uncertainty to ensure work productivity and organisational efficiency. Handling employees with compassion makes them feel valued, enables recovery from physical and psychological stress, and improves their commitment to the organisation (Grant et al., 2008; Lilius et al., 2008). Thus, compassionate leadership strives to enhance the happiness and wellbeing of their employees by supporting them with a conducive environment to excel. As they create compassionate environments in which employees can perform at the highest possible level, organisational leaders, through their interactions, can directly affect the work engagement of employees (Truss et al., 2013).

Employee engagement is a positive attitude held by the employee towards the organisation and its values (Robinson et al., 2004). These positive, fulfilling work-related attitudes are exhibited in employees' vigour, dedication, and absorption with work (Schaufeli et al., 2002). Engagement also requires passion and complete association with the job (Rich et al., 2010). Similarly referred to as job engagement, it encompasses an employee's interest in, enthusiasm for, and investment in his/her job, which yields positive outcomes for both the employee and the organisation (Kirkpatrick, 2007). Employee engagement is thus one of the key determinants of the success of an organisation but is affected by various factors such as personal characteristics, job characteristics, job status, and job demands (Hoole \& Bonnema, 2015; Mauno et al., 2007). Besides, employees tend to be engaged at work in circumstances where they can ascribe meaningfulness, safety, and availability. Tasks that grant autonomy, challenge, dignity, and worthwhileness attract more work commitment and engagement (Kahn, 1990). Consequently, employees will be more engaged in situations where there is more freedom of expression and where they feel needed, essentially implying that high levels of work engagement are dependent on an individual's current psychological state (Rothmann \& Rothmann Jr, 2010).

The health of one's psychological state at work is also dependant on whether they derive meaning in the work they are engaged in. Meaning in work is facilitated by personal growth and motivation influenced by some elements such as job enrichment, work role fits, and coworker relations (May et al., 2004). Organisational leaders are thus tasked with creating environments where relational contracts are built on commitment and trust. A safe space where co-worker relations are supportive, trustworthy, and open tends to be reciprocated with high levels of engagement (Cartwright \& Holmes, 2006; Kahn, 1990; May et al., 2004; Saks, 2006). However, the challenging reality is that most of these arguments support work engagement in 
in-person settings; how can they be applied to remote or virtual workspaces with no physical presence of an immediate supervisor.

The education sector in Rwanda and Uganda was not spared during the country-wide lockdown in February and March 2020, respectively. Stakeholders were encouraged to embrace Elearning, but in environments where in-person learning and working were the norms, higher learning institutions grappled with internalising the concept of E-Learning given its associated limitations in developing countries. The staff and students in many of the universities in Uganda had not fully experienced E-Learning and remote working. Thus, students and staff lacked the requisite skills, equipment, and infrastructure for delivering and attending lectures on online platforms. These inadequacies, coupled with the uncertainty of the COVID-19 pandemic lockdown, created stressful situations for all stakeholders in higher learning institutions. Much less the fact that Virtual work environments tend to be characterised by remote work, telecommuting, telework, and working from home, which are synonymously associated with feelings of isolation that employees may face. Kerber \& Buono (2004) argued that leaders need to make it possible for employees to constantly communicate and virtual networking with others to realign themselves to the organisation's goal and vision continually. Guided by the social exchange theory, this study focused on the staff in higher learning institutions whose work patterns have been distorted by the COVID-19 pandemic.

The social exchange theory attempts to explain the behaviour of individuals in business activities (Homans, 1958). It posits that employees can get engaged in work at different levels and degrees depending on the level of encouragement and motivation they receive from the employer. Furthermore, employee behaviours are conditioned to reciprocity and repayment rules (Saks, 2006). According to the social exchange theory, the trust between individuals and the expectations that the other party will fulfil their unspecified obligation guides the relationship in business. Thus, the way the manager communicates, rewards, and demonstrates effective leadership will significantly influence employee performance in virtual work environments. Besides, the successful use of technology in virtual work settings encourages collaboration, cooperation, and sharing, key aspects necessary for social exchange.

Groups that experience higher levels of interaction are more likely to have a strong sense of belonging and compassion. When a person feels valued by other group members, their selfesteem tends to rise. It is argued that employees who report high self-esteem tend to show better levels of performance compared to those with low self-esteem (Ferris et al., 2010; Moon et al., 2016; Pierce \& Gardner, 2004). Therefore, as Dutton et al. (2014) argued, the interaction between employees in the organisation helps promote compassionate behaviours. Where compassion means bearing the sufferings of oneself and others, it exists where people care, show patience, kindness, perseverance, and willingness to help (Choudhary et al., 2017). Compassion breeds trust and often involves providing resources such as time and show of concern required by an employee to manage stressful situations (Powley, 2009). Therefore, in stressful conditions such as the COVID-19 pandemic lockdown, this study sought to investigate the effect of organisational compassion on employee engagement in virtual workspaces in higher learning institutions in Uganda and Rwanda.

\section{Methods}

The study covered 1 year in 2020, during which work in many countries moved to remote settings due to the outbreak of the Covid - 19 pandemics. To determine how organisational compassion and employee engagement interacted with each other through virtual work settings across different environments, Uganda and Rwanda were chosen to offer a more diverse sample. The focus on universities was to gain more homogeneous data rather than spread it to 
all educational institutions. For this study, both secondary and primary sources of data were used. The primary sources of data included staff working in selected institutions of higher learning in Uganda and Rwanda. A link was sent to the selected higher institution employees requesting them to fill in a structured online questionnaire through purposive sampling. However, the online survey had limitations that pertained to the cost of and limited internet connectivity and constant power failures. Although there was a slow response rate, the researchers constantly sent reminders to the targeted participants through WhatsApp messages and telephone calls.

The survey had 2 sections: section A for demographic information that included questions on gender and nature of university work (Academic and or Administrative or purely Administrative) and section $\mathrm{B}$ with items for each of the variables under observation. The scaling and constructs for indicators adopted in this study are in line with the contextual framework propounded by Utrecht Work Engagement Scale (UWES) and Pommier's Compassion Scale (Schaufeli \& Bakker, 2004; Pommier, 2010). To capture responses in line with the temporal scope of the study, the constructs for the organisational compassion index were built around the mindfulness and kindness of (a) Self to Others, (b) Supervisor, and (c) Co-workers. The constructs for employee engagement were, on the other hand, built around (a) Vigour, (b) Dedication, and (c) Absorption. The items under both employee engagement in virtual work environments and organisational compassion were anchored on a 5-point Likert scale. Where 5 showed that employees were always engaged and 1 never engaged while working from home or virtually, concerning organisational compassion 5 represented situations where employees felt that they almost always exhibited a high sense of both kindness and mindfulness of self to others, by co-workers and supervisors and with 1 representing almost never at the opposite end of the scale. To facilitate a more cohesive description of indicators, codes for main and sub-indicators were used, as showed in table 1.

Table 1: Indicators and codes used in the study

\begin{tabular}{ll}
\hline Indicator & Code \\
\hline Organisational Compassion [Composite] & OrgComp \\
Kindness & Kin_StO \\
The kindness of Self to Others & Kin_Sup \\
Kindness of Supervisor & Kin_CoWork \\
Kindness of Co-workers & \\
Mindfulness & Min_StO \\
Mindfulness of Self to Others & Min_Sup \\
Mindfulness of Supervisor & Min_CoWork \\
Mindfulness of Co-workers & EmpEng.Comp \\
Employee Engagement [Composite] & Vig.Comp \\
Employee's Vigour & Ded.Comp \\
Employee's Dedication & Abs.Comp \\
Employee's Absorption &
\end{tabular}

Source: Authors' description

\section{Results}

To ensure for validity and reliability of the instrument's constructs, data from 102 respondents was tested for its normality, validity, and reliability using SPSS V.23. Using the D' Agostino skewness test and Anscombe - Glynn Kurtosis test (Oztuna et al., 2006; Sekaran, 2003), the 
test results showed no significant deviation from a normal distribution for the sample's constructs (Refer table 2).

Table 2: Statistical Normality Tests for the Scaled Constructs $[\mathrm{n}=102]$

\begin{tabular}{lll}
\hline & Organisation Compassion [OrgComp] & Employee Engagement [EmpEng.Comp] \\
\hline $\mathrm{N}$ & 102 & 102 \\
Mean & 65.30 & 34.44 \\
Std. Deviation & 16.043 & 11.709 \\
Minimum & 20 & 0 \\
Maximum & 96 & 60 \\
Skewness & -.373 & -.326 \\
Kurtosis & .474 & -.130 \\
\hline
\end{tabular}

Note. The overall score for each construct is based on average totals of the responses to appropriate items. Source. Field survey, 2020. Values are based on authors' calculations using SPSS V. 23

Validity and reliability tests were also conducted using the Pearson's Product moment correlation, and Cronbach alpha (Tavakol \& Dennick, 2011) were used. Consequently, implications of the internal consistency and reliability test conducted in this study point to the results derived from the constructs used $(\alpha=.890)$ to exceed the minimally acceptable range falling in the range of 'very good' (Tavakol \& Dennick, 2011). Similarly, with all values for constructs (OrgComp., and Emp.EngComp) satisfying the $<.05$ significance criteria, all constructs were considered valid.

Moreover, to establish the effect of organisational compassion on employee engagement in virtual workspaces, a simple linear regression analysis (Ordinary Least Square Method - OLS) on sub-constructs for Employee Engagement and Organisational compassion was conducted. The purpose of the linear model was to determine the underlying strength structure of association indicators on employees' engagement at different levels while working virtually. Furthermore, this approach allowed the model to identify the best fitting predictors to each indicator and estimate the contribution of each of the assessed predictor constructs (dependent variables) to the total variance explained. As such, using a simple regression structural formulation, the following model was constructed:

OrgComp $=\beta_{0}+\beta_{1}($ Vig.Comp $)+\beta_{2}($ Ded.Comp $)+\beta_{3}($ Abs.Comp $)+\varepsilon$

Whereby: OrgComp $=$ Organisational Compassion, $\beta_{0}=$ Constant, Vig.Comp $=$ Employee Engagement - Vigour, Ded.Comp $=$ Employee Engagement - Dedication, Abs.Comp $=$ Employee Engagement - Absorption, $\dot{\varepsilon}=$ The standard error term, $\beta_{0}, \beta_{1}, \beta_{2}$, and $\beta_{3}=$ Priority sign for coefficients of each construct variable $>0$

\section{Correlational Results of Indicators}

\section{The Impact of Kindness on Employees' Engagement}

As one of the sub-constructs building the compassion scale, kindness was assessed at its subscale level (Kin_Sto, Kin_Sup, and Kin_CoWork) to understand better how organisation compassion impacted employees' engagement. To achieve this, all the constructs were linearly correlated together with the employees' engagement composite construct yielding weak but significant impacts (Refer to table 3). In particular, the issue of how supervisors are kind to subordinates stood as the better predictor of how employees remain engaged at their work, $R_{x y}=.370$ with a $\quad$ p-value of .05 . 
Table 3: Correlation Coefficients - The Impact of Kindness on Employees' Engagement $(\mathbf{n}=\mathbf{1 2 0})$

\begin{tabular}{lrrrrc}
\hline Model & $R_{x y}$ & \multirow{2}{*}{$R^{2}$} & Adjusted $R^{2}$ & $\begin{array}{l}\text { Std. Error of } \\
\text { the Estimate }\end{array}$ & $\begin{array}{l}\text { Sig. } \\
\text { Change }\end{array}$ \\
\hline EmpEng.Comp, Kin_Cowork & $.319^{* *}$ & .102 & .093 & .657 & .00108 \\
EmpEng.Comp, Kin_StO & $.348^{* *}$ & .121 & .112 & .649 & .00033 \\
EmpEng.Comp, Kin_Sup & $.370^{* *}$ & .137 & .128 & .644 & .00013 \\
EmpEng.Comp, Kin.Compa & $.465^{* *}$ & .216 & .192 & .620 & .00002 \\
\hline
\end{tabular}

Note. ${ }^{* *}$ Correlation is significant at $\mathrm{p}<0.05$; a. Predictors: (Constant), Kin_CoWork, Kin_StO, Kin_Sup.

Source. Field survey, 2020. Values are based on the author's calculations using SPSS 23.

\section{The Impact of Mindfulness on Employees' Engagement}

To provide additional support to understanding the compassion scale at the organisational level, the sub-constructs of the Mindfulness scale (Min_StO, Min_Sup, and Min_CoWork) were linearly regressed with the employees' engagement composite construct (Table 4)

Table 4: Correlation Coefficients - The Impact of Mindfulness on Employees' Engagement $(\mathbf{n}=120)$

\begin{tabular}{lccccc}
\hline Model & $R_{x y}$ & \multirow{2}{*}{$R^{2}$} & Adjusted $R^{2}$ & $\begin{array}{l}\text { Std. Error of } \\
\text { the Estimate }\end{array}$ & $\begin{array}{l}\text { Sig. } \\
\text { Change }\end{array}$ \\
\hline EmpEng.Comp, Min_StO & $.452^{* *}$ & .204 & .196 & .618 & .00000 \\
EmpEng.Comp, Min_Sup & $.365^{* *}$ & .133 & .124 & .645 & .00016 \\
EmpEng.Comp, Min_CoWork & $.357^{* *}$ & .128 & .119 & .647 & .00023 \\
\hline
\end{tabular}

Note. ${ }^{* *}$ Correlation is significant at $\mathrm{p}<0.05$

Source. Field survey, 2020. Values are based on the author's calculations using SPSS 23.

Furthermore, correlations in table 4 above found positive correlations but relatively weak and significant with a p-value of .05 . Moreover, while the results showed that the correlations were not significantly different, the issue of mindfulness of self to others, $R_{x y}=.452$ in influencing employees' engagement, offered a more substantial predictive impact than supervisors' and coworkers' mindfulness.

\section{The Impact of Organisational Compassion on Employees' Engagement}

As the central premise for the study, the primary constructs for organisational compassion (Mindfulness \& Kindness) were used to construct a composite construct to explain organisational compassion impact on employee engagement. From the 102 observations recorded from respondents, a composite indicator was constructed using the mean totals scores from all observations for the indicators, correlated and tested against the three sub-indicators that make up employee engagement (Vigour, Dedication, and Absorption). As indicated in Table 5, results showed a significant partial correlation with the issue of organisation compassion on employees' vigour $R_{x y}=.513$ with a p-value of .05 compared to employees' dedication and absorption with $R_{x y}=.471$ and $R_{x y}=.293$ assessment at the same p-value of .05. This is indicative, in general terms, of how organisational compassion is a significant predictor of employees' vigour.

Table 5: Correlation Coefficients - The Impact of Organisational Compassion on Vigour, Dedication, and Absorption ( $\mathbf{n}=\mathbf{1 2 0})$

\begin{tabular}{llclll}
\hline Model & $R_{x y}$ & \multirow{2}{*}{$R^{2}$} & Adjusted $R^{2}$ & $\begin{array}{l}\text { Std. Error of } \\
\text { the Estimate }\end{array}$ & $\begin{array}{l}\text { Sig. } \\
\text { Change }\end{array}$ \\
\hline Vig.Comp & $.513^{* *}$ & .263 & .256 & .705 & .0000 \\
Ded.Comp & $.471^{* *}$ & .222 & .214 & .775 & .0000 \\
Abs.Comp & $.293^{* *}$ & .086 & .077 & .738 & .0028 \\
\hline
\end{tabular}

Note. ${ }^{* *}$ Correlation is significant at $\mathrm{p}<0.05$.

Source. Field survey, 2020. Values are based on the author's calculations using SPSS 23. 
Furthermore, when tested against the employees' composite construct (Vigour, Dedication, and Absorption), the model showed that, as a whole, there is a significant partial correlation with the whole issue of organisation compassion. Also, it showed how it impacts employees' engagement at different levels within the organisations' functional departments, $R_{x y}=.506$ with a p-value of .05 .

\section{The Influence of Organisational Compassion Predictor Construct on Employees' Engagement}

The resulting model from the regression analysis in table 6 that was aimed at assessing how organisational compassion affects employees' engagement in virtual workspaces during the Covid - 19 pandemic lockdowns reveal that the model is significant and less significantly fit to explain the influence of all predictor variables (independent variables) $\mathrm{R} 2=.283$. Hence, given their statistical significance $(\mathrm{p}<.05)$, the model significantly explains the predictor variable for employees' vigour.

Table 6: Influence of Organisational Compassion Predictor Construct on Employees' Engagement

\begin{tabular}{|c|c|c|c|c|}
\hline \multicolumn{5}{|l|}{ Model Summary } \\
\hline & $\mathrm{R}$ & $\mathrm{R}^{2}$ & Adj. $\mathrm{R}^{2}$ & Std. Error Est. \\
\hline & .532 & .283 & .261 & .577 \\
\hline \multicolumn{5}{|l|}{ Coefficients } \\
\hline \multirow[t]{2}{*}{ Model } & \multicolumn{2}{|c|}{ Unstandardised Coefficients } & $\begin{array}{l}\text { Standardised } \\
\text { Coefficients }\end{array}$ & Sig. \\
\hline & $\beta$ & Std. Error & $\beta$ & \\
\hline$\beta_{0}$ & 1.740 & .181 & & $.000 * *$ \\
\hline$\beta_{1}=$ Vig.Comp & .292 & .105 & .356 & $.000 * *$ \\
\hline$\beta_{2}=$ Ded.Comp & .150 & .100 & .196 & $.137 *$ \\
\hline$\beta_{3}=$ Abs.Comp & .024 & .088 & .028 & $.784 *$ \\
\hline
\end{tabular}

Note. $* *$ Significant at $\mathrm{p}<.05, *$ Significant at $\mathrm{p}<.01, \mathrm{~F}=12.894$, d.f $=3$.

Source. Field survey, 2020. Values-based on authors' calculations using SPSS 23

For predictor variables on employees' engagement and absorption, the regression results show that organisational compassion is not the best estimator under the null hypothesis for the study $(\mathrm{p}>.05)$.

\section{Discussion and conclusion}

This paper sought to establish if organisational compassion had any influence on employee engagement in virtual workspaces during the Covid-19 pandemic lockdown and the results, in general, indicated that organisational compassion was a significate predictor of the vigour component of employee engagement compared to dedication and absorption while working virtually and at home. When compassion was tested at the workplace against employee performance, findings revealed that compassion towards employees enhanced their task performance in combination with intrinsic motivation (Choudhary et al., 2017). An in-depth analysis of two selected dimensions of compassion (kindness and mindfulness) expressed by self to others, co-workers, and at the supervisory level revealed that kindness from a supervisor towards employees was a better predictor of employee work engagement. Employees who received compassionate feelings of affection, generosity, care, and tenderness from their supervisors had reduced work burnout, were more engaged at their work, and exhibited positive acts such as organisational citizenship behaviours and knowledge sharing (Eldor, 2018). In service sectors such as educational institutions that are susceptible to demanding stressful clients, limited resources, and high administrative workload, Eldor (2018) notes that compassion provides a vital coping mechanism. 
The supervisor's kindness towards employees was a better predictor of employees' work engagement. There is an assumed trickle-down effect when supervisors show compassion to their subordinates which in turn is reciprocated by subordinates to their fellows, which consequently builds an organisation with shared beliefs, practices, and quality relationships that in turn enhance performance (Choudhary et al., 2017; Dutton et al., 2014). As for mindfulness, employees' mindfulness of self to others was a stronger predictor of their work engagement compared to supervisor or co-worker mindfulness. Mindfulness of self to others ensured that one was present in the moment and accepted it for what it is and is also known to positively affect work engagement (Brown \& Ryan, 2003; Kiken \& Shook, 2011; Shapiro et al., 2006).

Virtual workspaces with all their attendant characteristics, such as isolation and loneliness, significantly burden the moral well-being of employees. But with additional support from supervisors and co-workers, employees' work engagement and productivity are enhanced. Thus, while compassion, as depicted by the results, significantly impacted employees' work vigour, the supervisor's kindness and employees' mindfulness of self to others greatly boosted employees' work engagement. Thus, it can be assumed that compassionate leadership and regular communication with workers via online platforms help foster team support and offer the necessary coping mechanism to adapt to virtual workspaces.

\section{References}

Andersson, M., \& Engervall, M. (2017). The Relationship Between Mindfulness and Work-Related Stress (pp. 119). Hogskolan Kristianstad. http://www.diva-portal.org/smash/get/diva2:1105962/FULLTEXT01.pdf

Atkins, P. W. B., \& Parker, S. K. (2012). Understanding Individual compassion in organisations: The role of appraisals and psychological flexibility. Academy of Management Review, 37(4), 524-546.

Brown, K. W., \& Ryan, R. M. (2003). The benefits of being present: Mindfulness and its role in psychological well-being. Journal of Personality and Social Psychology, 84(4), 822-848.

Carmody, J., \& Baer, R. A. (2008). Relationships between mindfulness practise and levels of mindfulness, medical and psychological symptoms, and well-being in a mindfulness-based stress reduction program. Journal of Behavioral Medicine, 31, 22-33.

Cartwright, S., \& Holmes, N. (2006). The meaning of work: The Challenge of regaining employee engagement and reducing cynicism. Human Resource Management Review, 16(2), 199-208.

Chen, C. A. (2012). Explaining the difference of work attitudes between public and non-profit managers: The views of rule constraints and motivational styles. The American Review of Public Administration, 42, 437460.

Choudhary, S., Ismail, A., \& Hanif, R. (2017). Individual compassion leading to employees' performance: An empirical study from Pakistan. Journal of Management and Research, 4(1), 77-89.

Cotney, J. L., \& Banerjee, R. (2019). Adolescents' conceptualisation of kindness and its links with well-being: A focus group study. Journal of Social and Personal Relationships, 36, 599-617.

Dane, E. (2011). Paying attention to mindfulness and its effects on task performance in the workplace. Journal of Management, 37(4), 997-1018.

Datu, J. A. D., \& Park, N. (2019). Perceived school kindness and academic engagement: The mediational roles of achievement goal orientations. School Psychology International, 40(5), 456-473.

Davies, A., Fidler, D., \& Gorbis, M. (2011). Future Work Skills2020. University of Phoenix Research Institute. https://www.iftf.org/uploads/media/SR-1382A_UPRI_future_work_skills_sm.pdf

Dutton, J. E., Workman, K. M., \& Hardin, A. E. (2014). Compassion at Work. Annual Review of Organizational Psychology, 1, 277-304.

Eldor, J. (2018). Public Service Sector: The Compassionate Workplace-the effect of compassion and stress on employee engagement, burnout, and performance. Journal of Public Administration Research and Theory, 28(1), 86-103. https://doi.org/10.1093/jopart/mux028

Ferris, D. L., Lian, H., Brown, D. J., Pang, F. X. J., \& Keeping, L. M. (2010). Self-esteem and job performance: The moderating role of self-esteem contingencies. Personnel Psychology, 63, 561-593. https://doi.org/10.1002/hfm.20615

Grant, A. M., Dutton, J. E., \& Rosso, B. D. (2008). Giving commitment: Employee support programs and the prosocial sense-making process. Academy of Management Journal, 51(5), 898-918.

Homans, G. C. (1958). Social Behaviour as Exchange. American Journal of Sociology, 63(6), 597-606.

Hoole, C., \& Bonnema, J. (2015). Work engagement and meaningful work across generational cohorts. SA Journal of Human Resource Management, 13(1), 1-11. 
International Labour Organization [ILO]. (2020). COVID-19 and the World of Work: Impact and Policy Responses. International Labour Organization.

Kahn, W. A. (1990). Psychological Conditions of Personal Engagement and Disengagement at Work. Academy of Management Journal, 33(4), 692-724.

Kerber, K. W., \& Buono, A. F. (2004). Leadership challenges in global virtual teams: Lessons from the field. SAM Advanced Management Journal, 69(4), 4-10.

Kiken, L. G., \& Shook, N. J. (2011). Looking up: Mindfulness increases positive judgments and reduces negativity bias. Social Psychological and Personality Science, 2(4), 425-431.

Kirkpatrick, C. (2007). To invest, coast or idle: Second-stage teachers enact their Job engagement. American Educational Research Association Annual Conference.

Lilius, J. M., Worline, M. C., Maitlis, S., Dutton, J. E., \& Frost, P. (2008). The contours and consequences of compassion at work. Journal of Organizational Behaviour, 29, 193-218.

Mauno, S., Kinnunen, U., \& Ruokolainnen, M. (2007). Job demands and resources as antecedents of work engagement: A longitudinal study. Journal of Vocational Behaviour, 70, 149-171.

May, D. R., Gilson, R. L., \& Harter, L. M. (2004). The psychological conditions of meaningfulness, safety, and availability, and the engagement of the human spirit at work. Journal of Occupational and Organizational Psychology, 77, 11-37.

Moon, T.-W., Hur, W.-M., Ko, S.-H., Kim, J.-W., \& Yoo, D.-K. (2016). Positive Work-Related Identity as a Mediator of the Relationship between Compassion at Work and Employee Outcomes. Human Factors and Ergonomics in Manufacturing \& Service Industries, 26(1), 84-94.

Neff, K. D. (2003). The Development and Validation of a Scale to Measure Self-Compassion. Self and Identity, 2 , 223-250. https://doi.org/10.1080/15298860390209035

Okechukwu, E. U., Egbo, D. E., \& Isikuru, H. O. (2017). Effect of virtual management on employee performance in selected E-Business firms in Lagos State, Nigeria. International Journal of Academic Research in Economics and Management Sciences, 6(3), 241-229.

Oztuna, D., Elhan, A. H., \& Tuccar, E. (2006). Investigation of four different normality tests in terms of type 1 error rate and power under different distributions. Turkish Journal of Medical Sciences. 36 (3), pp. $171-$ 176.

Park, N., \& Peterson, C. (2006). Moral competence and character strengths among adolescents: The development and validation of the values in action inventory of strengths for youth. Journal of Adolescence, 29, 891905.

Peters, L. M., \& Manz, C. C. (2007). Identifying antecedents of virtual team collaboration. Team Performance Management, 13(3/4), 117-129. https://doi.org/10.1108/13527590710759865

Pierce, J. L., \& Gardner, D. G. (2004). Self-esteem within the work and organisation context: A review of the organisation-based self-esteem literature. J.Manag., 30, 591-622.

Pommier, E. A. (2010). The Compassion Scale. The University of Texas.

Powell, A., Piccoli, G., \& Ives, B. (2004). Virtual Teams: Team control Structure, Work Processes, and Team Effectiveness. Information Technology and People, 17, 359-379.

Powley, E. H. (2009). Reclaiming resilience and safety: Resilience activation in the critical period of crisis. Human Relations, 62(9), 1289-1326. https://doi.org/10.1177/0018726709334881

Rich, B. L., LePine, J. A., \& Crawford, E. R. (2010). Job engagement: Antecedents and effects on job performance. Academy of Management Journal, 53, 617-635.

Robinson, D., Perryman, S., \& Hayday, S. (2004). The Drivers of Employee Engagement (No. 408; pp. 1-87). $\begin{array}{llll}\text { Institute for } & \text { Employment } & \text { Studies. }\end{array}$ studies.co.uk/system/files/resources/files/408.pdf

Rothmann, S., \& Rothmann Jr, S. (2010). Factors associated with employee engagement in South Africa. SA Journal of Industrial Psychology, 36(2), 1-12.

Saks, A. M. (2006). Antecedents and consequences of employee engagement. Journal of Managerial Psychology, 21(7), 600-619.

Schaufeli, W. B., \& Bakker, A. B. (2004). Job demands, job resources and their relationship with burnout and engagement: A Multi-sample study. Journal of Organizational Behaviour, 25(3), 393-315.

Schaufeli, W. B., Salanova, M., Gonzalez-Roma, V., \& Bakker, A. B. (2002). The Measurement of Engagement and Burnout: A Two-Sample Confirmatory Factor Analytic Approach. Journal of Happiness Studies, 3, 71-92.

Schepp, D., \& Schepp, B. (1995). The Telecommuter's Handbook: How to earn a living without going to the office. McGraw-Hill Ryerson Ltd.

Shapiro, S. L., Carlson, L., \& Astin, J. (2006). Mechanisms of mindfulness. Journal of Clinical Psychology, 62(3), 373-386.

Sekaran, U. (2003). Research Methods for Business A Skill-Building Approach (4 ${ }^{\text {th }}$ Ed.). John Wiley \& Sons, New York. 
Tavakol, M., \& Dennick, R. (2011). Making Sense of Cronbach's Alpha. International Journal of Medical Education, 2, 53-55.

Truss, C., Shantz, A., Soane, E., Alfes, K., \& Delbridge, R. (2013). Employee engagement, organisational performance, and individual well-being: Exploring the evidence, developing the theory. The International Journal of Human Resource Management, 14, 2657-2669. https://doi.org/10.1080/09585192.2013.798921

Ume, L. M., \& Javed, A. (2019). Effect of mindfulness on Job burnout and work engagement. Effect of Mindfulness on Job Burnout and Work Engagement, 7(4), 265-276.

Vogus, T. J., \& Sutcliffe, K. M. (2012). Organisational mindfulness and mindful organising: A reconciliation and path forward. Academy of Management Learning and Education, 11(4), 722-735.

Weinstein, N., Brown, K. W., \& Ryan, R. M. (2009). A multi-method examination of the effects of mindfulness on stress attribution, coping, and emotional well-being. Journal of Research in Personality, 43, 374-385.

Wiroko, E. P., \& Evanytha, E. (2019). Mindfulness and work engagement among generation Y. Psycho Idea, $17(2), 154-163$. 